\title{
Application and evaluation research on group decision-making model in English teaching
}

\author{
Wei Dong, Ying Shi, Chunyi Lou \& Yan Ding \\ Qinhuangdao Institute of Technology, Qinhuangdao, Hebei, China
}

\begin{abstract}
This paper researches the issues of English teaching by the use of the group decision-making hierarchical structural assessment model, which aims at clearly resolving the problems in the examination of the current English teaching, and quickly provides effective solutions. The group decision-making hierarchical structural assessment model can ultimately construct a quantitative index assessment system based on the weight analysis and combined with the multi-index quantification mode, thus flexibly and effectively solving fuzzy and complex problems. This paper will build a group decision-making hierarchical structural assessment model for English teaching in China, establish factors affecting level and measures scheme level, make a detailed quantitative weight evaluation analysis and find out an educational method that can effectively enhance the practicability of English in China.
\end{abstract}

Keywords: English teaching; group decision-making model; hierarchical structural analysis

\section{INTRODUCTION}

In recent four decades of reform and opening up, the socialist road with Chinese characteristics has gone through a comprehensive preliminary construction. In this period, China's policy and society also have entered a new stage of development, and China's economy also has had a rapid development. Due to the enhancement of China's comprehensive strength, China also plays an important role in the international community.

With China's growing impact on the international community, China's economy, culture and society also integrate with the world. Due to the diversified nature of the economy, culture and society, and English is the second language in China and the most popular language all around the world, the requirements on the popularization and education quality of English are also increased correspondingly. So far, English has occupied an ever-growing proportion in the personnel cultivating programs in China. As Chinese people pay more attention to the education of English and the implementation of the system of English teaching, more and more English teaching mecha- nisms are created so that English education industry has become very complex. However, due to the defects in the philosophy of guidance, unclear educational goals and other reasons, China's English education is mostly the exam-oriented education, resulting that many personnel lack good practicability on English. However, China's current international situation should highlight the practicability of English education. Therefore, it is necessary to reform its status quo.

With the improvement of science and technology and advent of the era of big data, the scope of application for the fuzzy statistics becomes wider. The quantitative weight evaluation method based on the group decision-making hierarchical structural model has a very effective application in many fields, which can empower based on a lot of references and relevant experience of the experts, thus finding out practical solutions. Therefore, this paper will establish the group decision-making hierarchical structural model for English teaching in China, make a detailed quantitative weight evaluation analysis of its future development direction, and finally find out an educational method that can effectively enhance the practicability of English in China. 


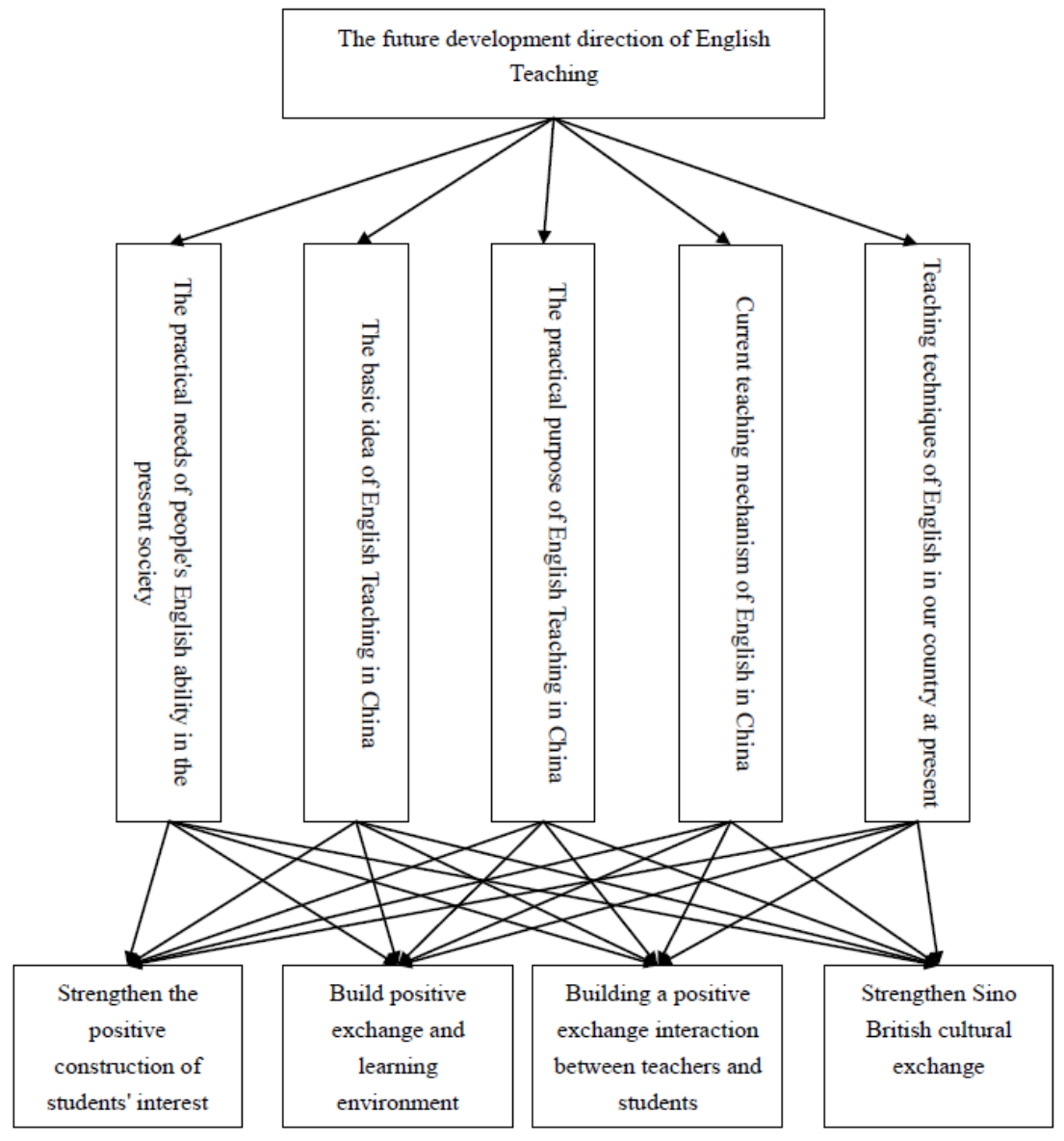

Figure 1. Hierarchical structure

\section{RESEARCH ON QUANTITATIVE WEIGHT ASSESSMENT OF ENGLISH TEACHING IN CHINA}

\subsection{Group decision-making hierarchical structural analysis model of English teaching}

Nowadays, China has a greater impact on the international community, and various fields in China have a greater requirement on the practicability of English. Therefore, to oppose the exam-oriented education, emphasize the practicability of English in life and then improve the quality of national English is the primary objective of English teaching in China. In order to analyze the future development direction of English teaching in China, this paper first establishes the group decision-making hierarchical structural analysis model for the future development direction of English teaching in China, and quantifies all kinds of influence factors and schemes, and establishes a relation between the target layer, criterion layer and scheme layer.

Target layer: future development direction of English teaching.

Criterion layer: influence factors of schemes. $x_{1}$ is the practical needs of English in society, $x_{2}$ is the basic idea of English teaching in China, $x_{3}$ is practical purpose of English teaching, $x_{4}$ is English teaching mechanism, and $x_{5}$ is the existing technique of English teaching.

Scheme layer: $y_{1}$ is to strengthen the positive construction of students' interest, $y_{2}$ is to build a positive exchange and learning environment, $y_{3}$ is to build a benign exchange interaction between teachers and students, $y_{4}$ is to strengthen Sino-British cultural exchange to obtain a hierarchical structure, as shown in Figure 1.

According to the experience of a large number of experts, the reference of the extensive literature and the scaling settings of $1-9$, the comparison matrixes are as Table 1.

Table 1. Scale table

\begin{tabular}{|l|l|}
\hline Scale $a_{i j}$ & Definition \\
\hline 1 & Factor $\mathrm{i}$ is equally important to factor $\mathrm{j}$ \\
\hline 3 & Factor $\mathrm{i}$ is slightly important than factor $\mathrm{j}$ \\
\hline 5 & Factor $\mathrm{i}$ is more important than factor $\mathrm{j}$ \\
\hline 7 & Factor $\mathrm{i}$ and factor $\mathrm{j}$ are very important \\
\hline 9 & Factor $\mathrm{i}$ and factor $\mathrm{j}$ are absolutely important \\
\hline $2,4,6,8$ & $\begin{array}{l}\text { Scale value corresponding to the intermediate } \\
\text { state between above judgment }\end{array}$ \\
\hline Reciprocal & $\begin{array}{l}\text { If the factor } \mathrm{i} \text { and factor } \mathrm{j} \text { are relatively weak, } \\
\text { the judgment value is a reciprocal }\end{array}$ \\
\hline
\end{tabular}


Table 2. Comparison matrix

\begin{tabular}{|l|lllll|}
\hline $\mathrm{G}$ & $x_{1}$ & $x_{2}$ & $x_{3}$ & $x_{4}$ & $x_{5}$ \\
\hline$x_{1}$ & 1 & $1 / 2$ & 3 & 2 & 4 \\
$x_{2}$ & 2 & 1 & 2 & 4 & 5 \\
$x_{3}$ & $1 / 3$ & $1 / 2$ & 1 & 3 & 3 \\
$x_{4}$ & $1 / 2$ & $1 / 4$ & $1 / 3$ & 1 & 1 \\
$x_{5}$ & $1 / 4$ & $1 / 5$ & $1 / 3$ & 1 & 1 \\
\hline
\end{tabular}

Table 3. Comparison matrix

\begin{tabular}{|l|llll|}
\hline$x_{1}$ & $y_{1}$ & $y_{2}$ & $y_{3}$ & $y_{4}$ \\
\hline$y_{1}$ & 1 & 2 & 3 & 3 \\
$y_{2}$ & $1 / 2$ & 1 & 2 & 2 \\
$y_{3}$ & $1 / 3$ & $1 / 2$ & 1 & 1 \\
$y_{4}$ & $1 / 3$ & $1 / 2$ & 1 & 1 \\
\hline
\end{tabular}

Table 4. Comparison matrix

\begin{tabular}{|l|llll|}
\hline$x_{2}$ & $y_{1}$ & $y_{2}$ & $y_{3}$ & $y_{4}$ \\
\hline$y_{1}$ & 1 & 4 & 2 & $1 / 3$ \\
$y_{2}$ & $1 / 4$ & 1 & $1 / 2$ & 4 \\
$y_{3}$ & $1 / 2$ & 2 & 1 & 2 \\
$y_{4}$ & 3 & $1 / 4$ & $1 / 2$ & 1 \\
\hline
\end{tabular}

Table 5. Comparison matrix

\begin{tabular}{|l|llll|}
\hline$x_{3}$ & $y_{1}$ & $y_{2}$ & $y_{3}$ & $y_{4}$ \\
\hline$y_{1}$ & 1 & $1 / 2$ & 3 & 4 \\
$y_{2}$ & 2 & 1 & 4 & 5 \\
$y_{3}$ & $1 / 3$ & $1 / 4$ & 1 & $1 / 2$ \\
$y_{4}$ & $1 / 4$ & $1 / 5$ & 2 & 1 \\
\hline
\end{tabular}

Table 6. Comparison matrix

\begin{tabular}{|l|llll|}
\hline$x_{4}$ & $y_{1}$ & $y_{2}$ & $y_{3}$ & $y_{4}$ \\
\hline$y_{1}$ & 1 & 3 & 3 & 2 \\
$y_{2}$ & $1 / 3$ & 1 & 1 & 3 \\
$y_{3}$ & $1 / 3$ & 1 & 1 & 3 \\
$y_{4}$ & $1 / 2$ & $1 / 3$ & $1 / 3$ & 1 \\
\hline
\end{tabular}

Table 7. Comparison matrix

\begin{tabular}{|l|llll|}
\hline$x_{5}$ & $y_{1}$ & $y_{2}$ & $y_{3}$ & $y_{4}$ \\
\hline$y_{1}$ & 1 & 2 & 3 & 2 \\
$y_{2}$ & $1 / 2$ & 1 & $1 / 2$ & $1 / 2$ \\
$y_{3}$ & $1 / 3$ & 2 & 1 & $1 / 2$ \\
$y_{4}$ & $1 / 2$ & 2 & 2 & 1 \\
\hline
\end{tabular}

According to the formula $C I=\frac{\lambda_{\max }-n}{n-1}$, we can calculate $C I$ and obtain the consistency of analysis, and finally obtain the consistency reasonableness of $C$.
That is, the judgment matrix passes the consistency test by the use of the above principle.

$$
\begin{aligned}
C_{1} & =\left\{\begin{array}{cccc}
1 & 2 & 3 & 3 \\
1 / 2 & 1 & 2 & 2 \\
1 / 3 & 1 / 2 & 1 & 1 \\
1 / 3 & 1 / 2 & 1 & 1
\end{array}\right\}, C_{2}=\left\{\begin{array}{cccc}
1 & 4 & 2 & 1 / 3 \\
1 / 4 & 1 & 1 / 2 & 4 \\
1 / 2 & 2 & 1 & 2 \\
3 & 1 / 4 & 1 / 2 & 1
\end{array}\right\}, \\
C_{3} & =\left\{\begin{array}{cccc}
1 & 1 / 2 & 3 & 4 \\
2 & 1 & 4 & 5 \\
1 / 3 & 1 / 4 & 1 & 1 / 2 \\
1 / 4 & 1 / 5 & 2 & 1
\end{array}\right\}, C_{4}=\left\{\begin{array}{cccc}
1 & 3 & 3 & 2 \\
1 / 3 & 1 & 1 & 3 \\
1 / 3 & 1 & 1 & 3 \\
1 / 2 & 1 / 3 & 1 / 3 & 1
\end{array}\right\}, \\
C_{5} & =\left\{\begin{array}{cccc}
1 & 2 & 3 & 2 \\
1 / 2 & 1 & 1 / 2 & 1 / 2 \\
1 / 3 & 2 & 1 & 1 / 2 \\
1 / 2 & 2 & 2 & 1
\end{array}\right\}
\end{aligned}
$$

Corresponding maximum eigenvalues and eigenvectors are as follows:

$\lambda_{\max }^{(0)}=\frac{1}{5}\left(\frac{2.278}{0.289}+\frac{2.276}{0.201}+\frac{0.765}{0.240}+\frac{0.637}{0.140}+\frac{0.338}{0.130}\right)=4.15$,
$i^{(0)}=\left\{\begin{array}{l}0.289 \\ 0.201 \\ 0.240 \\ 0.140 \\ 0.130\end{array}\right\}$

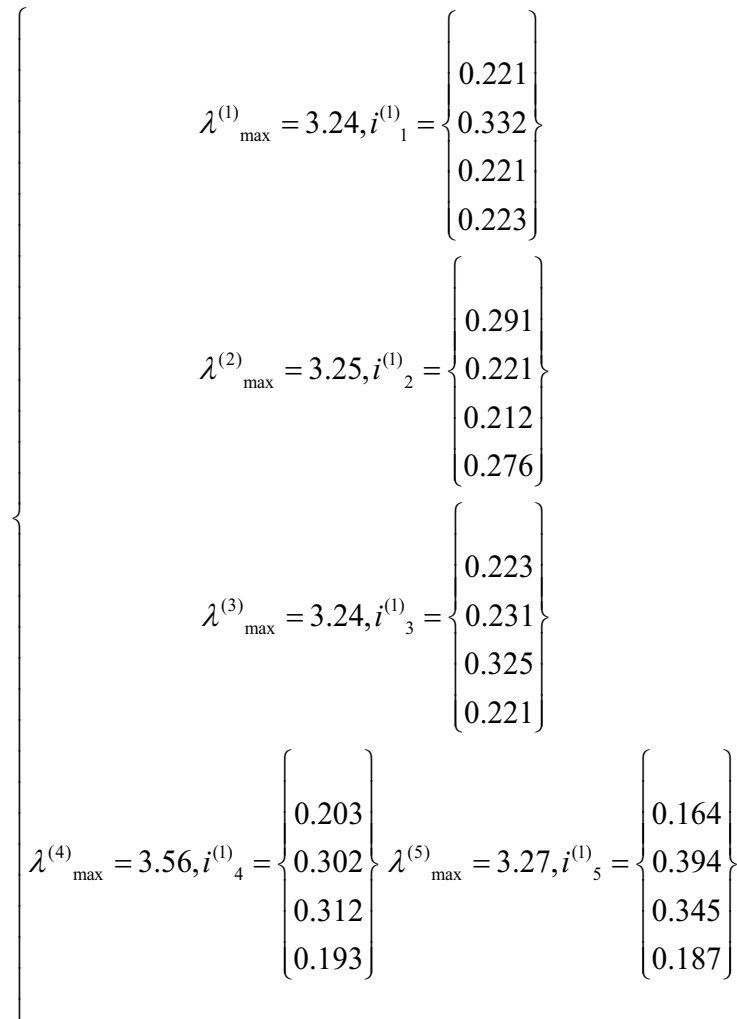

\subsection{Solution to quantitative weight evaluation of English teaching in China}

Test the reasonableness of weight value by the use of 
the consistency indicators:

$C I=\frac{\lambda_{\max }-n}{n-1}, C R=\frac{C I}{R I}$

RI can be obtained as shown in Table 8 .

Obtaining the judgment matrix $A$,

$\lambda_{\text {max }}^{(0)}=4.15, R I=0.9$.

$C I=\frac{4.15-4}{4-1}=0.24$

$C R=\frac{C I}{R I}=\frac{0.024}{0.90}=0.027<0.1$

The result is less than 0.1 , indicating that the result of the consistency test is reasonable, and $A$ moves within a permissible range so that the eigenvectors obtained by solving the matrix $A$ can be regarded as the weight vectors for description. The calculation results of the target layer and scheme layer can be obtained by the consistency test of the judgment matrix, as shown in Figure 2.
Computation structure is as follows:

$i^{(1)}=\left(i_{1}^{(1)}, i_{2}^{(1)}, i_{3}^{(1)}, i_{4}^{(1)}, i_{5}^{(1)}\right)$

$$
=\left\{\begin{array}{lllll}
0.221 & 0.291 & 0.223 & 0.203 & 0.164 \\
0.332 & 0.221 & 0.231 & 0.302 & 0.394 \\
0.221 & 0.212 & 0.325 & 0.312 & 0.345 \\
0.223 & 0.276 & 0.221 & 0.193 & 0.187
\end{array}\right\}
$$

$i=i^{(1)} i^{(0)}$

$$
=\left\{\begin{array}{lllll}
0.221 & 0.291 & 0.223 & 0.203 & 0.164 \\
0.332 & 0.221 & 0.231 & 0.302 & 0.394 \\
0.221 & 0.212 & 0.325 & 0.312 & 0.345 \\
0.223 & 0.276 & 0.221 & 0.193 & 0.187
\end{array}\right\}\left\{\begin{array}{c}
0.289 \\
0.201 \\
0.240 \\
0.140 \\
0.130
\end{array}\right\}=\left\{\begin{array}{l}
0.334 \\
0.233 \\
0.220 \\
0.213
\end{array}\right\}
$$

According to the above analysis, the educational method of the practicability of English in China is restricted greatly by the social needs, teaching aims, teaching mechanisms and teaching techniques. Therefore, the future development direction of English teaching in China must set up reasonable teaching schemes for the impact of the actual needs of English

Table 8 . RI values

\begin{tabular}{|l|l|l|l|l|l|l|l|l|l|l|l|}
\hline $\mathrm{n}$ & 1 & 2 & 3 & 4 & 5 & 6 & 7 & 8 & 9 & 10 & 11 \\
\hline $\mathrm{RI}$ & 0 & 0 & 0.58 & 0.90 & 1.12 & 1.24 & 1.32 & 1.41 & 1.45 & 1.49 & 1.51 \\
\hline
\end{tabular}

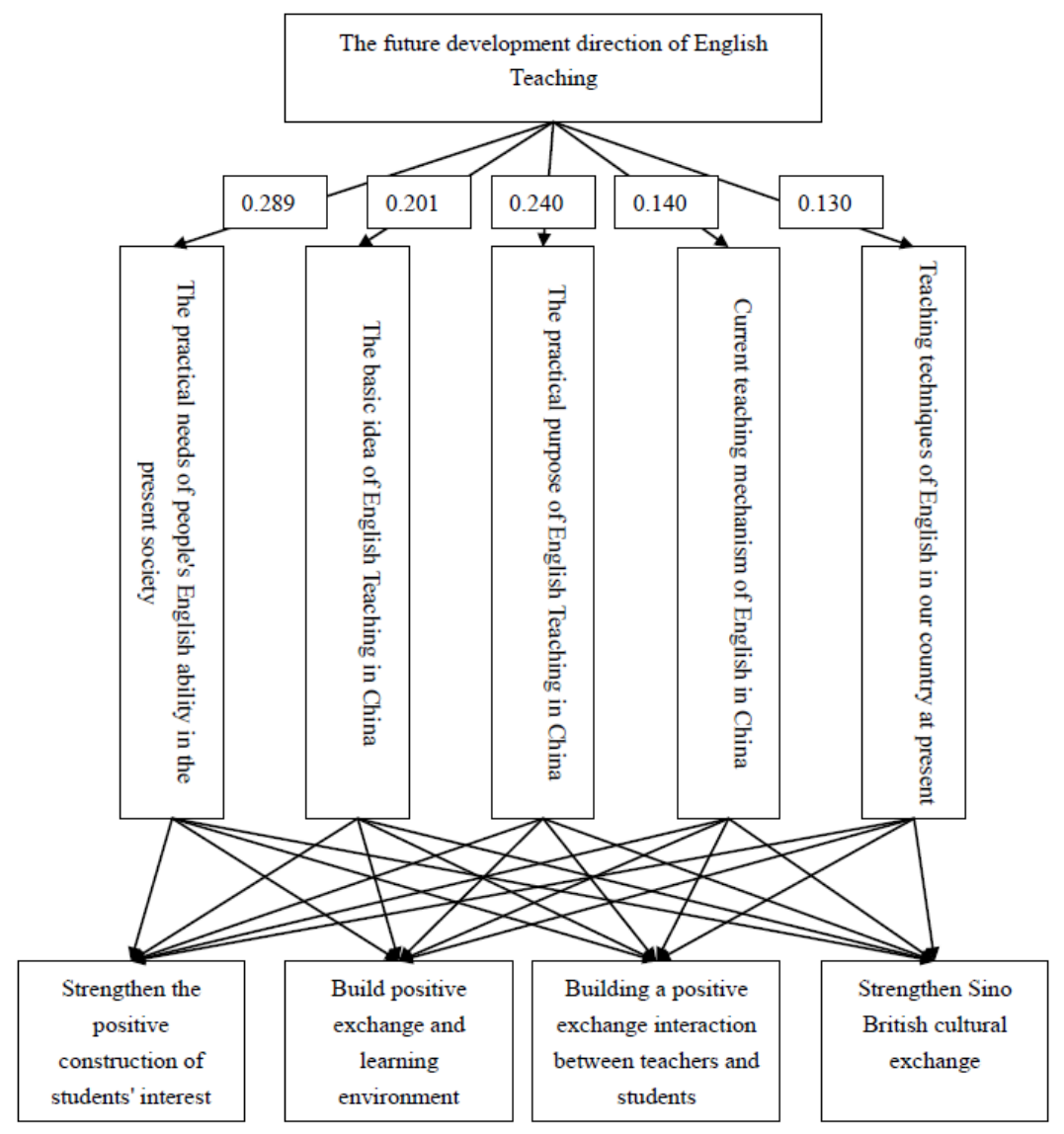

Figure 2. Calculation results of the target layer and scheme layer 
in society, basic idea of English teaching in China, practical purpose of English teaching, English teaching mechanism and existing technique of English teaching.

This paper makes a quantitative weight evaluation on the future development direction of English teaching in China through the establishment of the group decision-making hierarchical structural model, and achieves that the important strategies of implementing practical English teaching in China are to strengthen the positive construction of students' interest, build a positive exchange and learning environment, build a benign exchange interaction between teachers and students and strengthen Sino-British cultural exchange, with their respective weights of $0.334,0.233,0.220$ and 0.213 .

\section{CONCLUSION}

This paper carries out the research of the quantitative weight evaluation for the future development direction of English teaching in China, establishes the group decision-making hierarchical structural analysis model based on a large number of experience of experts, analyzes the impact of the actual needs of English in society, basic idea of English teaching in China, practical purpose of English teaching, English teaching mechanism and existing technique of English teaching, and finds out the optimal solution. That is, we should strength the positive construction of students' interest, build a positive exchange and learning environment, build a benign exchange interaction between teachers and students and strengthen Sino-British cultural exchange.
It indicates that, in order to achieve the practical education of English in China, there is a need to first change the educational concept of English in China, establish a positive teacher-student interaction system, advocate the professional and practical education of English and avoid the exam-oriented education; what's more, we should also focus on cultivating the students' interest, strengthening the Sino-British cultural exchange, building a good language communication environment and developing their ability to practically use English, thus realizing the practical education of English in China.

\section{REFERENCES}

[1] Hu Kaibao \& Xie Lixin. 2014. Research on the future development direction of college English teaching in China. Foreign Language World, (3).

[2] Wang Shouren. 2013. Adhere to the scientific concept of reform of college English teaching. Foreign Language World, (6).

[3] Wang Shouren. 2013. Some thoughts on academic English teaching. Chinese Language, (5).

[4] Yu Xia. 2002. Exploratory research on the impact of contradictions between needs and demands on the teaching effect in teaching English for specific purpose. China's Doctorate and Master's Theses Database, (4).

[5] Wu Qiong \& Wang Bo. 2010. Reform of teaching means and methods of college English. Science and Education, (3).

[6] Jin Can. 2010. Primary exploration of the reform of English teaching method in vocational education. Journal of National Teachers College of Qinghai Normal University, (1).

[7] Zhao Long. 2010. Research on the method of cultural teaching reform of college English. Journal of Henan University of Urban Construction, (3). 